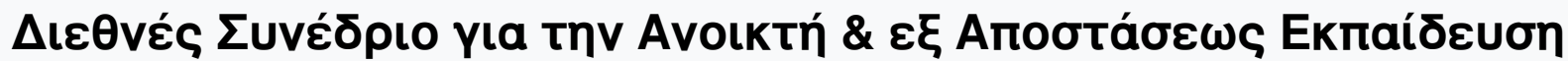

Tón. 7, Ap. 4A (2013)

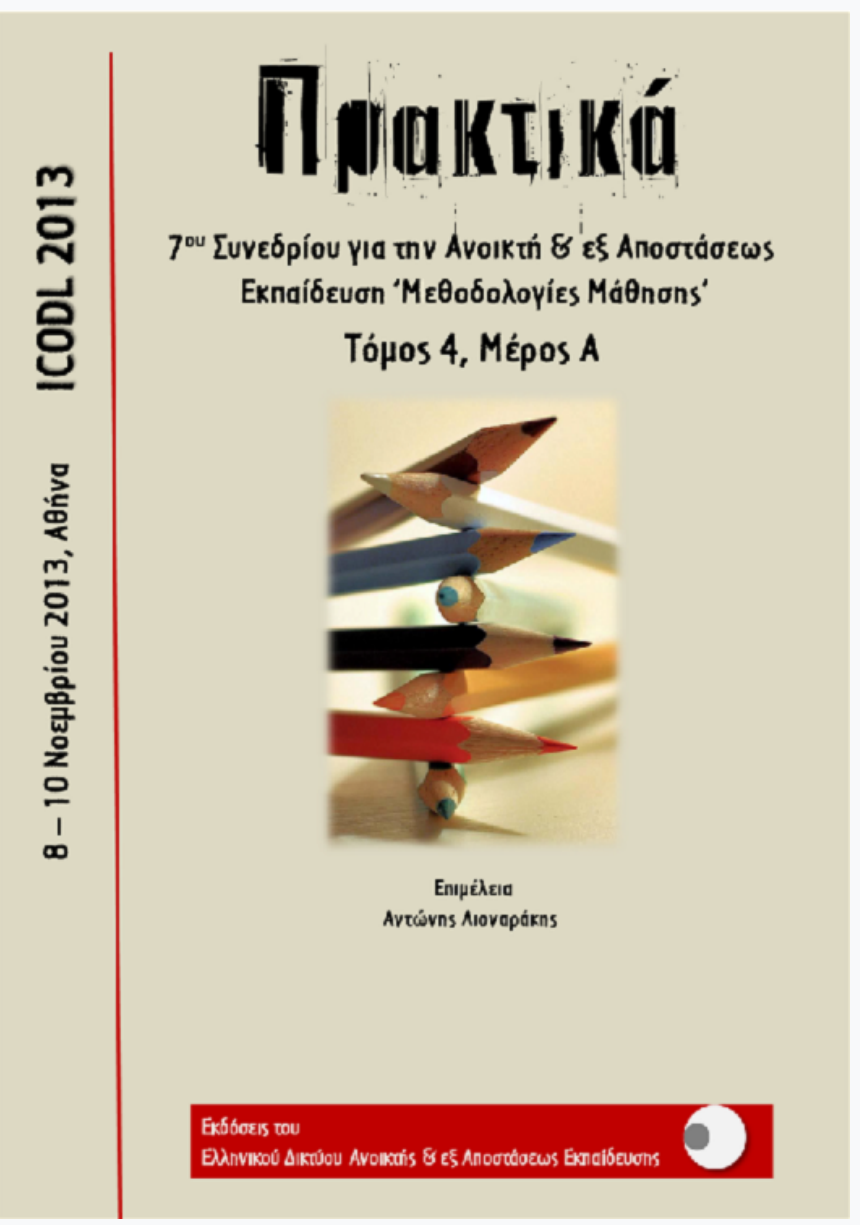

Improvement of the dissertation assignment procedure at Master's Degree Programs: The case of HOU MBA program

Athanassios Mihiotis

doi: $10.12681 /$ icodl. 717 


\title{
Improvement of the dissertation assignment procedure at Master's Degree Programs: The case of HOU MBA program
}

\author{
Athanassios Mihiotis \\ Hellenic Open University \\ Associate Professor HOU, Academic Director MBA Program, HOU \\ mihiotis@eap.gr
}

\begin{abstract}
A dissertation is the prerequisite for receiving a Master's degree at the end of the course. Writing a dissertation presents one of the most creative challenges of this post-graduate program. Students are offered the opportunity to prove that they are in a position to use the knowledge they have gathered during their studies and to carry out research into a topic of their choice, related to the aims of the Program and under the guidance of a supervisor. This paper presents the dissertation assignment procedure at the MBA program of HOU. The assignment procedure rests on an automated matching system between supervisor's research topics and students who have applied for dissertation, aiming at the speedier completion of the dissertation procedure, as well as the improved quality of the elaborated thesis.
\end{abstract}

Keywords: Master's Degree, dissertation, assignment, supervision, matching

\section{Introduction}

The MBA Program offered by the Hellenic Open University (HOU) requires a dissertation in order to receive a Master's degree. Writing a dissertation is one of the most creative challenges of this post-graduate program. It offers students the opportunity to prove that they have the ability to employ the knowledge they have gathered during their studies in Business Administration and to carry out research into a topic of their choice, which is related to the aims of the Program. The work proceeds under the guidance of a supervisor.

A dissertation should bring in scientific originality (i.e. a possibility to lead either to a scientific publication in an academic journal or to an announcement at a national or International Academic Conference) and/or contribute with new knowledge on the topic examined. The content of a dissertation must create the ability to positively affect future research in that particular research area and enrich the knowledge of the author, supporting the achievement of his/her professional goals.

Dissertations are expected to be of high scholarly competence and of the highest academic standards. In this direction, the supervisor's role is crucial. His/her role is to help and guide the student in choosing the right topic and also to provide guidance and advice during the writing of the dissertation. He/she should comment, correct or improve the text of the dissertation submitted by the student on a regular basis, guide him/her and provide advice regarding the elaboration of the dissertation. To the extent that his/her research interests are close to those of the subject supervised, the chances for succeeding the highest academic standards are very high. 
According to White (2002) there are a number of stages involved in the production of a dissertation: area of interest identified; specific topic selected; topic refined to develop dissertation proposal; proposal written and approved; collection of data and information; analysis and interpretation of data/information; writing up; and final draft prepared - submission of dissertation.

At the HOU MBA program, which celebrates its tenth year of operation, each student carrying out a dissertation is supervised by a qualified academic instructor, who is assigned by the Academic Director of the MBA Program. The program Director, in order to assign dissertations to Associated Research Staff, first reviews a "preliminary" dissertation proposal submitted by the students, which he relates to the research interests and the overall academic profiles of the associated research staff.

Due to the fact that supervision takes place under distant learning conditions, the above-described role of supervisors is extremely crucial.

This paper presents a pilot implementation for dissertation assignments at the HOU MBA program, as applied during the last two academic years,; a matching research interest system between supervisors and students has been introduced for dissertations, aiming at speeding up the completion of the dissertation procedure as well as at improving the quality of elaborated thesis.

The rest of the paper describes HOU-specific regulations and procedures for students who work on a dissertation (Section 2), followed by the key elements of the above procedure revision (section 3) and finally, the preliminary results of the pilot implementation of the revised design are presented.

\section{Preparing and submitting a dissertation proposal}

According to HOU regulations, students who are registered and enrolled their last one or two modules, are eligible to submit a "preliminary" dissertation proposal, by completing the relevant form (Form A). Form A must be submitted to the Academic Registry for approval by the Academic Director. Each student carrying out a dissertation is supervised by a qualified academic instructor who is assigned by the Academic Director. After preparing the final assignment dissertation list, which gets published on the HOU website a month prior official assignments' announcement $\left(1^{\text {st }}\right.$ of October), students with the assistance of their supervisors may improve the dissertation proposal and next submit the "final" dissertation proposal (Form B) to the Registry (by the end of September). Form B must bear the original signature of the supervisor which implies that he approves of the final form of the proposal.

Up to academic year 2009-10, the dissertation proposal included the following (see old FORM A, App. 1; old Form B, App.2): Title of the dissertation, brief description of the topic, explanation of the importance of the topic and a statement of the reason(s) for undertaking the specific research project, preliminary Table of Contents, description of the methodology and stating which modules of the MBA program the topic of the dissertation relates to.

The entire submission process, from Form A to the final assignment of dissertations by the Program Director to supervisors must be completed in less than 10 days, which often leads assignments to a looser relationship between supervisors' research interests and the supervision of proposed topics of interest.

Interestingly enough, until the academic year 2009-10 the ratio between assigned dissertations appointed to associate research staff/ supervisors was almost the same for all program topics, independently of the number of associate research staff per 
topic and the number of announced dissertations. All members of the program's associate research staff supervised, on average, the same number of dissertations.

The MBA program consists of 4 distinct course modules, namely topic 50 (Economics for Managers), 51 (Financial Management \& Accounting), 60 (Advanced Quantitative Methods for Managers) and 61 (Management of People and Organizations).

From the time the Program Director assigns dissertation topics to the supervisors (within the first ten days of September), students and supervisors have less than two weeks in order to finalize the dissertation's subject (title, content, methodology).

The above mentioned subject completion involves a potential subject adjustment in order to match the supervisor's field of interests, the subject's radical change or even the rejection by the supervisor who might suggest another subject.

The above fact made it even harder to optimize the relationship "initial student subject - supervisor field of interest - final subject" with a direct consequence for the quality of the final deliverable (depth of research completion, etc.).

On the basis of all of he above, it was decided in 2010 (actually at the start of the academic year 2010-11) to design a different system able to correlate the subjects proposed by the students to the supervisors.

\section{Topic selection - correlation with supervisor's field of interest}

The topic of a dissertation must be accomplishable and precise. Students should select topics which allow them to make maximum use of their knowledge and analytical skills. The choice of a topic may varies from ideas inspired by discussions during group meetings or it may come from their own interests. The dissertation is an academic endeavor and therefore it may not be too general or simply a skills' exercise. A dissertation that combines academic rigor with practical application(s) is the ideal case.

Students should be aware that a dissertation topic usually combines four interacting factors (Fig.1), namely, the research area and the business sector that the dissertation will be positioned, the dissertations' classification and the most common methodology/tools employed. An area of research that interests the students must be selected. The definition of a research working hypothesis is the motivation of scientific process and the foundation of any research method and experimental design, from a realistic experimentation to a case study. Typically, a dissertation will employ data. Data should be validated and should originate from primary or secondary sources. Primary data come mainly from questionnaires, interviews etc. Secondary data are usually found in books, articles, published reports and electronic databases. The supervisor may assist the student regarding the type of data or information that is more suitable to the dissertation topic. He/she is also able to advise the student on appropriate methods, practices or tools for data collection. The methodology must be based on generally accepted principles that can be easily and precisely assessed. 


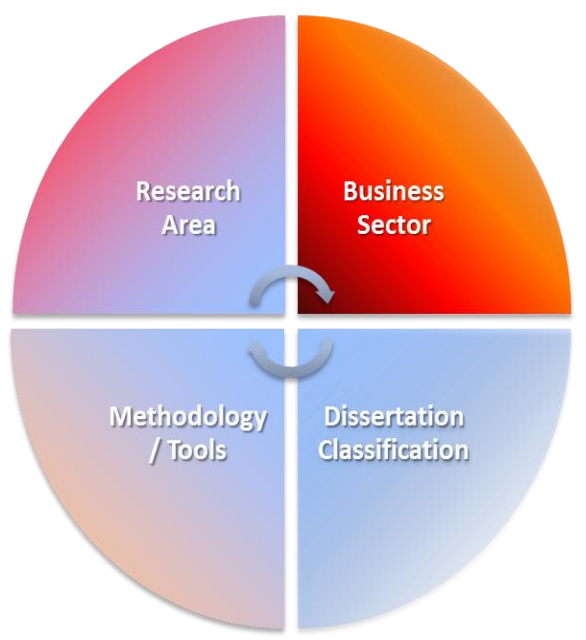

Fig. 1

Each one of the above four interacting factors was further analyzed (Fig.2) and included at the Dissertation Preparation Guide of the MBA program, in order to give direct access to the students as well as to the members of the associated research staff of MBA Program.

The aim of this project is, as already mentioned, to present ways to achieve a high level of correlation between the students' suggested subjects and the supervisors' fields of interest. The above fact was evaluated as yielding great importance by the program's administration. Therefore, and with the help of our scientific staff we started the revision of Forms A (see NEW Form A, App.3) and B (NEW Form B, App.4) and we designed a new Form C (Form C, App.5), which addresses exclusively potential supervisors and aims at optimizing the correlation between their respective fields of interest and the proposed by the students subjects.

Form C was first completed by the supervisors during the academic year 2011-12 and was submitted electronically to the program Director. Due to an absence of the proper on line support the director proceeded to the topic correlation and subsequent assignments related to supervisors' research interests, based on the research area only. During the next academic year 2012-13 we launched the electronic submission of all relevant Forms (A, B and C) and finalized the automation of the matching process. 


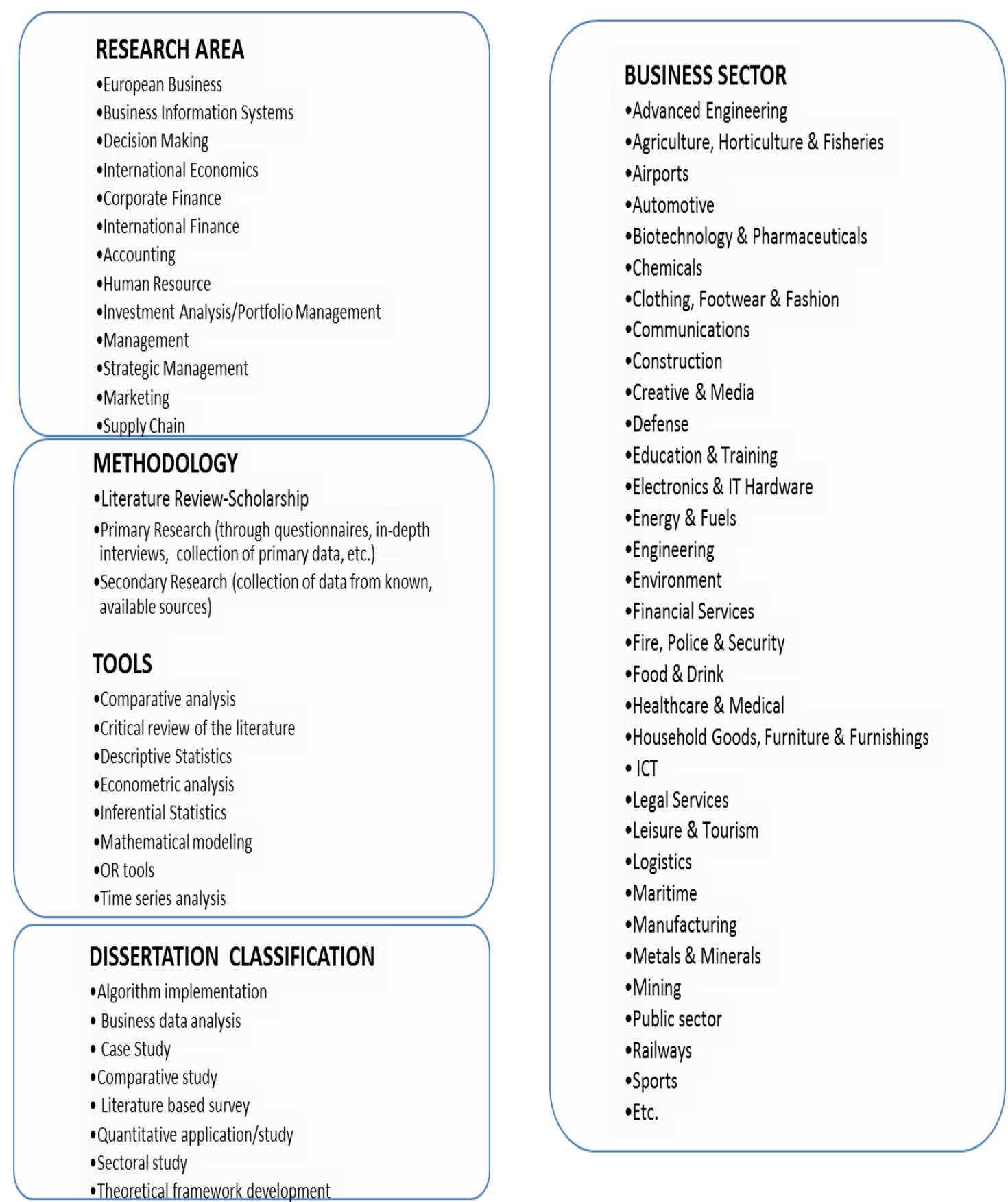

Fig. 2

\section{Conclusions}

According to Wagner et al. (2008), e-learning is a large and growing market with great potential in higher education and, in order to maximize this potential, e-learning implementations should endeavor to meet the needs and concerns of all stakeholder groups as much as possible.

The results from the introduction of the new, dissertation-and-supervisor-field-of interest-correlation system, received wide acceptance by the students, who responded with more comprehensive proposals on Form A while less time was spent by both students and supervisors on filling Form B, which no longer has to be signed by the supervisor since it was approved electronically. 
In addition, the time required for dissertation assignments by the program Director to the supervisors was reduced to more than half, while the correlation between dissertation subject assignment and the supervisors' field of interest improved significantly.

It is quite impressive that within the two years of this pilot implementation (2010-11, 2011-12) the distribution of dissertations per module of the program has radically changed (Fig 3), while, as mentioned, in the current academic year 2012-13 the ratio (per topic) between appointed dissertations and members of the associated research staff supervising, was significant different from previous years. Specifically, at module MBB50 it became $\sim 1$ assignment per member of the associated research staff, at module MBA60 became 2 assignments per member and at modules MBA51 and MBA61 $\sim 3$ assignments per member.

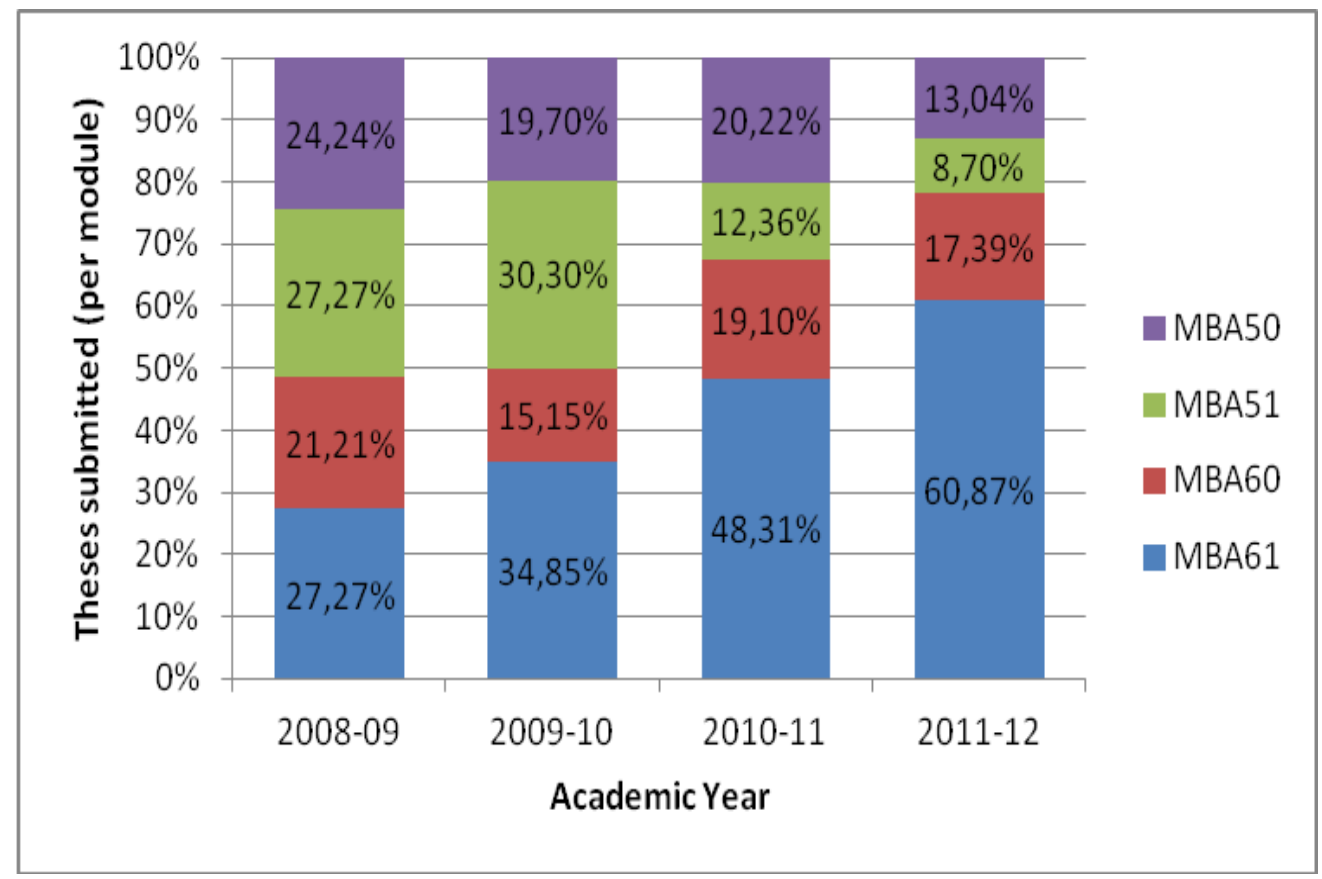

Fig. 3

With the full implementation of the application for the 2013-14 academic year, it is expected that the correlation between the introduction of this application with any variation of dissertation grading evaluation will be further monitored.

\section{Acknowledgements}

I would like to thank my colleagues lecturers at the MBA program for their comments during the project design and especially Dr Ioannis Lagoudis, Dr Nikitas-Spyros Koutsoukis, Dr Ioannis Theotokas, Dr Anastasia Konstantelou and Dr Nikos Rachaniotis for their valuable contribution to the final layout, as well as Dr Giannis Tsoulfas for the implementation of the overall plan into a software application.

\section{Bibliography}

Dissertation Handbook for the MBA program (2012), HOU

Wagner, N., Hassanein, K., and Head, M. (2008). Who is responsible for E-Learning Success in Higher Education? A Stakeholders' Analysis. Educational Technology \& Society, 11 (3), pp. 26-36.

White, B. (2002). Andover, Hampshire: Cengage Learning EMEA. 


\section{Appendix 1. Old Form A}

\section{HELLENIC OPEN UNTVERSITY}

To Registration Department

Posteraduate program: "Master in Business Administration (MBA)"

DISSERTATION PROPOSAL FORM

PLAN

Students Name/ Surname:

Student Registry No.

Address/number:

City / Area / country:

Email Postal Code:

Phone:

Fax:

Mobile Phone:

1. Proposed Dissertation title for the academic year

2. Brief description of Dis sertations subject

3. Explanation of subjects' importance and justification of students' interest in the dissertation topic.

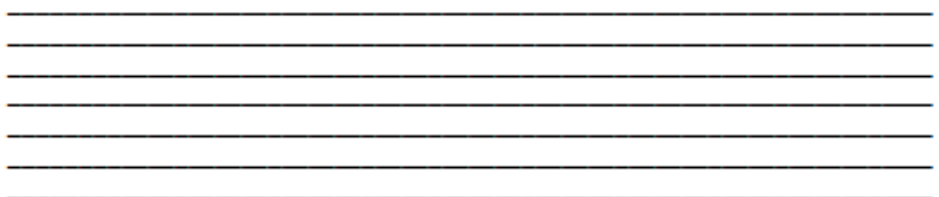

4. Provisional dissertation outline

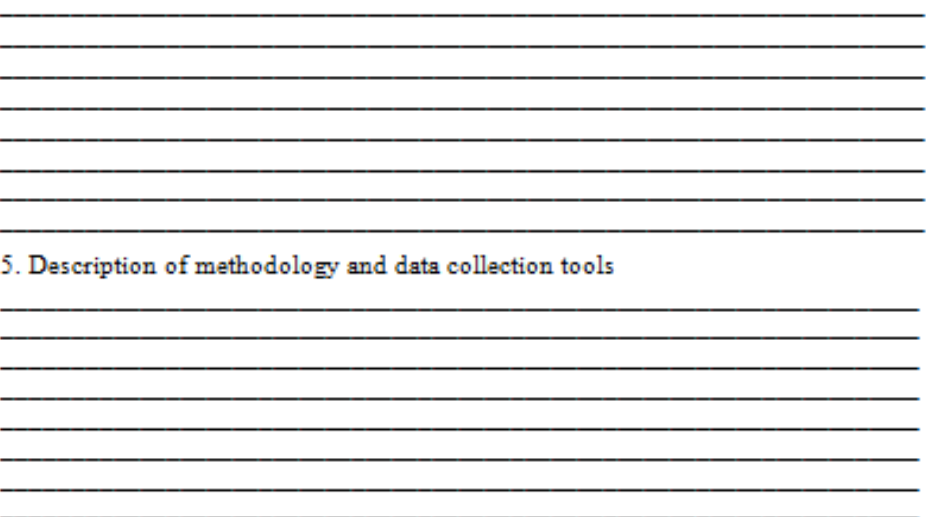

6. The dis sertations topic is clas sified in the following research area

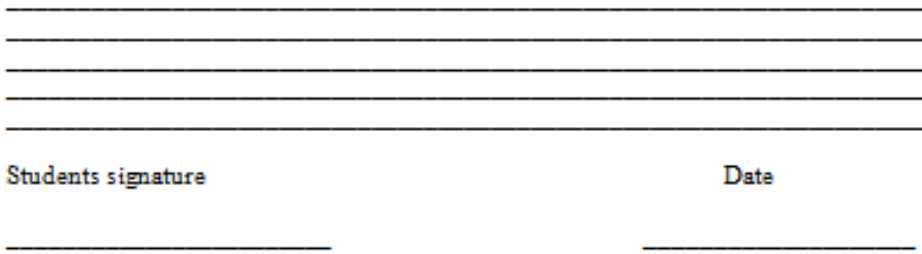

Academic Directors Approval: 


\section{Appendix 2. Old Form B}

HELLENIC OPEN UNTVERSITY

To Registration Department

Postgraduate program: "Master in Business Administration(MBA)"

\section{DISSERTATION PROPOSAL FORM}

FINAL

Students Name / Surname:

Student Registry No

Address/number:

City / Area/ country:

Email

Phone: $\quad$ Mobile Phone:

1. Proposed Dissertation title for the academic year

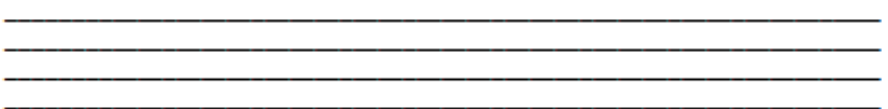

2. Brief description of Dis sertations subject

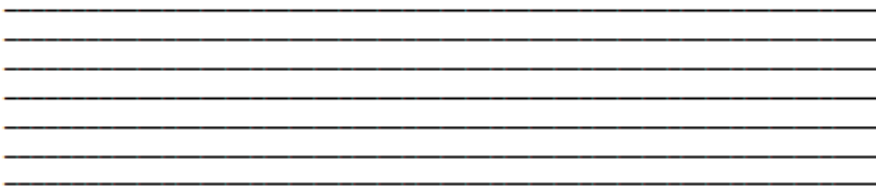

3. Explanation of subjects' importance andjustification of students' interest in the dissertation topic.

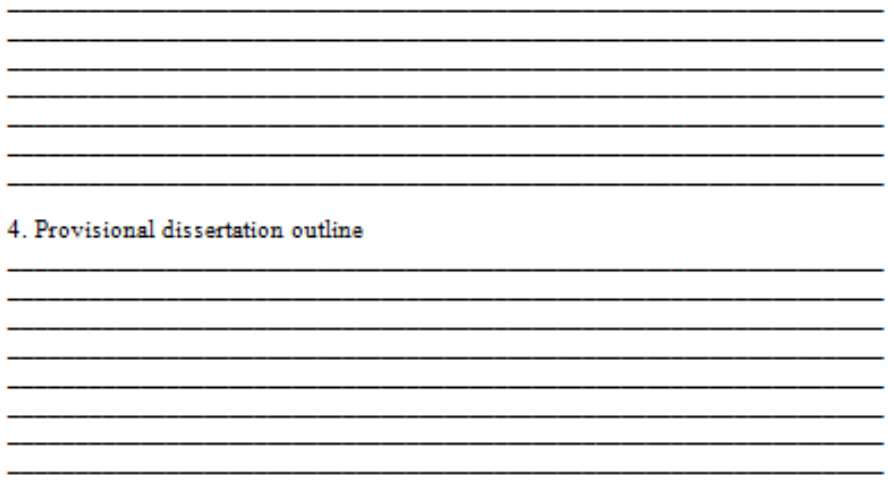

5. Description of methodology and data collection tools

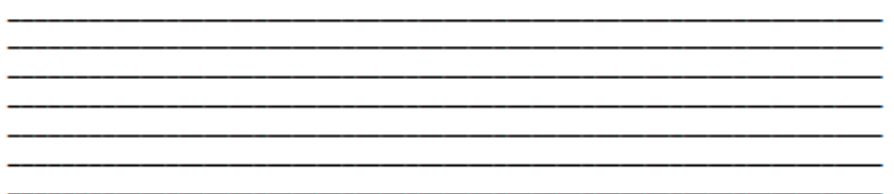

6. The dis sertations topic is clas sified in the following research area

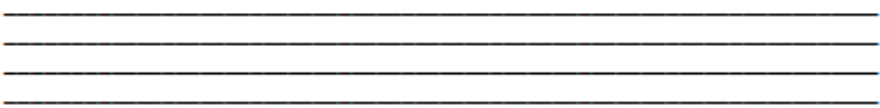

Appointed Supervis or

Approval committee member:

Students signature $\quad$ Supervisors signature Date

Academic Directors Approval 


\section{Appendix 3. New Form A}

\begin{tabular}{l} 
Mellenic Open University \\
Mas - Master in Business Administration \\
Master's Dissertation Proposal Form \\
\hline Part 1 - To be filled in by the Student \\
\hline 1A. Student Details (All fields required): \\
\begin{tabular}{|l|l|l|l|}
\hline Sumame: & & Name: & \\
\hline Student Registry No. & & Location (City): & \\
\hline Contact Tel.: & & Mobile Tel. & \\
\hline Email: & & \\
\hline
\end{tabular}
\end{tabular}

1B. Proposed Dissertation Title (s so worls with or without subtitle):

The proposed title should be as brief as possible but ciearly indicating the main focus of the dissertation. A subtith may be used in onder to clarify the topic of the dissertation. Do not phrase the propased title as a question and avoid wsing mumbers, buezwords or other context-specific linguistics within your (sub)titite.

\begin{tabular}{|l|} 
avodid using mombers, buezwords or other contex-specific linguistics within your (sub)titite. \\
\hline
\end{tabular}

1C. Brief Description ( $\leq 250$ words)

Try to provide a ciear statement of the problem and commuanioate your main ideas regarding the content, the method and the importance of the proposed work.

Relevance to Program Modules (Mark [X] as appropriate)

Module relievance is used for appointing Supervisors and $2^{\text {st }}$ Markers. While strong relevance to tovo modules is

\begin{tabular}{|l|c|c|c|}
\cline { 2 - 4 } \multicolumn{1}{c|}{ Module } & Strong & Modest & Weak / None \\
\hline MBA - 50 Economics for Managers & & & \\
\hline MBA - 51 Financial Management \& Acoounting & & & \\
\hline MBA -60 Advanced Quantitative Methods for Managers & & & \\
\hline MBA -61 Management of People \& Organisations & & & \\
\hline None of the above / Other Topics (please comment/specify): &
\end{tabular}

1E. Topic classification

The dassification cattegories are presented in the "Dissertation handbook for the Master's degree program in Bussiness Administration (MRA)" pp. 5-7

\begin{tabular}{|l|l|}
\hline Research Area & \\
\hline Methodology & \\
\hline Tools & \\
\hline Dissertation Classification & \\
\hline Business Soctor & \\
\hline
\end{tabular}

1F. Optional information

I have discussed my proposal with this possible(") Supervisor who is willing to undertake my supervision:

\begin{tabular}{|l|l|l|}
\hline Title \& Surname: & Module: MBA- \\
\hline
\end{tabular}

Provide any additional comments to the Academic Director ( $<80$ Words).
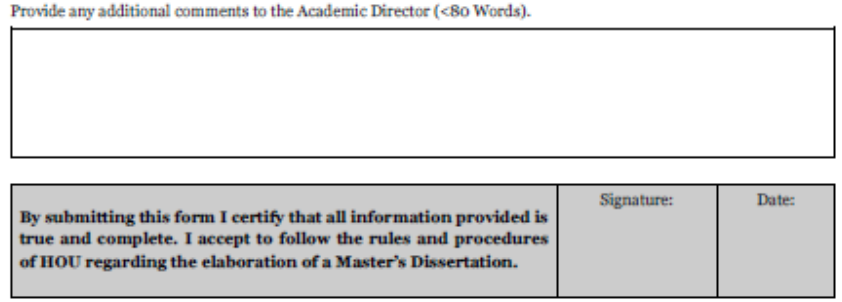

\section{Part 2 - To be filled in by the Academic Director}

2A. Proposal Outcome

\begin{tabular}{|r|l|l|l|l|}
\hline Approved: & & To be Revised/Return to student: & & Module: MBA. \\
\hline
\end{tabular}

2B. Supervisor Assignment

\begin{tabular}{|l|l|l|}
\hline Proposed Supervisor: & & Module: MRA- \\
\hline Propased 2 2a Markier: & & Module: MBA- \\
\hline
\end{tabular}




\section{Appendix 4. New Form B}

Hellenic Open University

MBA - Master in Business Administration

Master's Dissertation Proposal Form

B

Part 1 - To be filled in by the Student (Consult with Supervisor as appropriate)

A. Student Details (All fields required):

\begin{tabular}{|l|l|l|l|}
\hline Surname: & & Name: & \\
\hline Student Registry No. & & Location (City): & \\
\hline Contact Tel.: & & Mobile Tel.s & \\
\hline Email: & \multicolumn{3}{|l}{} \\
\hline
\end{tabular}

B. Dissertation Title:

C. Summary \& Importance of the topic ( $\$ 250$ worts)

D. Topic elassification

The classification categories are presented in the "Dissertation handbook for the Master's degree program in Business Administration (MRA) ${ }^{-}$pp. 5-7.

\begin{tabular}{|l|l|}
\hline Research Area & \\
\hline Methodology & \\
\hline Tools & \\
\hline Dissertation Classification & \\
\hline Business Sector & \\
\hline
\end{tabular}

E. Provisional Dissertation Outline [Chapter Titles / Main Headings].

\begin{tabular}{|l|l|l|}
\hline \multicolumn{1}{|c|}{ Outline [Required] } & \multicolumn{2}{|c|}{ Comments [Optional] } \\
\hline $\begin{array}{l}\text { 1. Introduction } \\
\text { 2. <Chapter Title } \\
\text { 3. <Chapter Title> } \\
\text { N-1. <Chapter Tritic } \\
\text { N. Conclusions }\end{array}$ & & \\
& & \\
& & \\
\hline $\begin{array}{l}\text { By submitting this form I certify that all information provided is } \\
\text { true and complete. I accept to follow the rules and procedures } \\
\text { of HOU regarding the elaboration of a Master's Dissertation. }\end{array}$ & Signature: & \\
\hline
\end{tabular}

Part 2 - To be filled in by the Appointed Supervisor

Supervisor Information

\begin{tabular}{|l|l|l|}
\hline Appointed Supenisor: & & Module MBA- \\
\hline By countersigning this form I certify that all information provided has my approval. \\
\hline Signature: & Date: \\
\hline
\end{tabular}




\section{Appendix 5. Form C}

Hellenic Open University

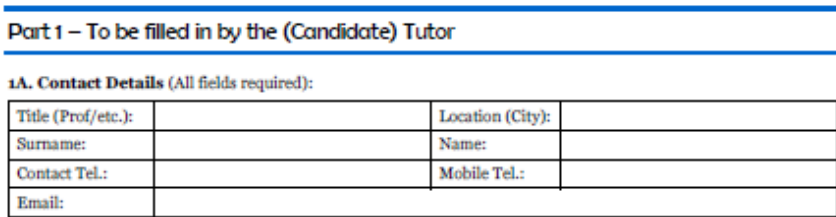

2A. MEA Thematic Units

Enter the two (2) TUs you applied for and then rank the units by relevance (1-stronger relevance)

\begin{tabular}{|c|c|c|}
\hline Thematic Units & Applied for ( $\leq z)$ & Relevance $(\leq 4)$ \\
\hline MB.45o Economics for Managers & & \\
\hline MB.451 Financial Management \& Accounting & & \\
\hline MB.A60 Aduanced Quantitative Methods for Managers & & \\
\hline MB.A61 Management of People \& Organisations & & \\
\hline
\end{tabular}

MB.A61 Management of People \& Organisations

2B. Dissertation Related Expertise
\begin{tabular}{|c|l|}
\hline X & Dissertation Research Area (Tick all that apply) \\
\hline & European Business \\
\hline & Business Information Systems \\
\hline & Decision Making \\
\hline & International Economics \\
\hline & Corporate Finance \\
\hline & International Finance \\
\hline & Accounting \\
\hline & Human Resource \\
\hline & Investment Analysis/Portfolio Management \\
\hline & Management \\
\hline & Strategic Management \\
\hline & Marketing \\
\hline & Supply Chain \\
\hline & Other (please specify below): \\
\hline
\end{tabular}

\begin{tabular}{|c|c|}
\hline \multicolumn{2}{|l|}{ Business Sector (Tick all t) } \\
\hline Advanced Engineering & Financial Services \\
\hline Agriculture, Horticulture \&\& Fisheries & Fire, Police \& Security \\
\hline Airports & Food \& Beverage \\
\hline Automotive & Healthcare \& Medical \\
\hline Biotechnology \& Pharmaceuticals & Household Goods, Furniture \& Furnishings \\
\hline Chemicals & \begin{tabular}{|l|} 
Information \& Communication Tech \\
\end{tabular} \\
\hline Clothing, Footwear \& Fashion & Legal Services \\
\hline Communications & Leisure \& Tourism \\
\hline Construction & Logistics \\
\hline Creative \& Media & Maritime \\
\hline Defense & Manufacturing \\
\hline Education \& Training & Metals \& Minerals \\
\hline Electronics \& IT Hardware & Mining \\
\hline Energy \& Fuels & \begin{tabular}{|l|} 
Public sector \\
\end{tabular} \\
\hline Engineering & Railways \\
\hline Environment & Sports \\
\hline None of the above & Other \\
\hline If "other" please specify. & \\
\hline
\end{tabular}

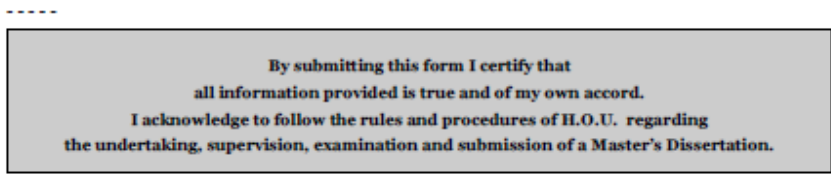

Part 2 - To be filled in by the Academic Director

\begin{tabular}{|c|c|}
\hline \multicolumn{2}{|c|}{ 2A. Assignment Information } \\
\hline Assigned to Student (1): & Reg. 0 \\
\hline Assignment (2): & Reg.e \\
\hline Assignment (3): & Reg.e \\
\hline Assignment (4): & Reg. 0 \\
\hline Assignment (5): & Reg.e \\
\hline $2^{n t}$ Examiner (1): & Reg.e \\
\hline $2^{24}$ Examiner (2): & Reg.e \\
\hline $2^{24}$ Examiner (3): & Reg.e \\
\hline $2^{\text {nd }}$ Examiner (4): & Reg.e \\
\hline 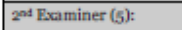 & Reg.e 0 \\
\hline Academic Director: & Date: \\
\hline
\end{tabular}

